\title{
Seasonal Variation in Contents of Sugars in Different Parts of Broccoli
}

\author{
Shiva Ram Bhandari and Jung-Ho Kwak* \\ Vegetable Research Division, National Institute of Horticultural and Herbal Science (NIHHS), Rural Development Administration (RDA), Wanju 565-852, \\ Korea
}

\begin{abstract}
Seasonal variation in the contents of sugars (fructose, glucose, and sucrose) in the floret, leaf, and stem of broccoli were studied in ten commercial broccoli cultivars. Plants were grown in the spring and fall seasons in 2011. In both seasons, glucose was the major constituent, comprising about $50 \%$ of the total sugar content in the floret and leaf tissue of most cultivars, whereas the broccoli stem showed an unusual pattern of accumulation. Sucrose exhibited greater cultivar dependency as well as seasonal variation compared to fructose and glucose in floret and leaf tissues. The floret tissue had a higher total content of sugar in the spring compared to the fall due to an increase in glucose and fructose. However, most of the leaf and stem tissues of broccoli had a higher total sugar content in the fall compared to the spring. Furthermore, stem and leaf tissues possessed a relatively higher total sugar content compared to floret tissue in both seasons. 'Grandeur' broccoli contained a significantly greater amount of total sugar in both floret and leaf tissues in both seasons, whereas 'YuDoRi No.1' broccoli exhibited the highest total content of sugar in stem tissue. At overall, the results showed significant influences of genotype, plant part and growing season on sugar content in broccoli.
\end{abstract}

Additional key words: floret, sugars, growing season, leaf, stem

\section{Introduction}

The carbohydrates are the primary compounds of metabolism that can be transported or temporarily stored, providing energy and C skeletons for the synthesis of other compounds (Rosa et al., 2001). They can signal to the cell to alter enzyme activity and gene expression, which regulate plant growth (Cheng et al, 2002). They are also used as precursors for the biosynthesis of a wide range of biomolecules such as lipids, proteins, and polysaccharides (Duffus and Duffus, 1984). In both vegetables and fruits, sweetness is the result of sugars such as fructose, glucose, and sucrose (Sims and Golaszewski, 2003) in that fructose gives most sweetness which was followed by sucrose and glucose (Joesten et al., 2007). Sugars not only affect the sweetness of vegetables and fruits, but they also alter the flavor and acceptability of vegetables (VandenLangenberg et al., 2012), as well as the perception of flavor sensations associated with other organic compounds (Auerswald et al., 1999). In tomato, increasing the amount of sugars while maintaining the level of organic acids increases the sweetness and preference of the fruit (Malundo et al., 1995). Likewise, in broccoli, an increase in sugar contents has been proposed as a way to mask the bitter taste of sulfur-containing glucosinolates and promote consumption (Schonhof et al., 2004), and it also plays an important role in the postharvest senescence of the vegetable (King and Morris, 1994). Furthermore, both glucose and fructose are glycoxidating agents and are capable of producing reactive compounds (Semchyshyn et al., 2014). The accumulation and concentration of sugars is dependent on several factors such as genotypes, type of tissues, developmental stages, and growing seasons (Hodges et al., 2006; Hounsome et al., 2008; Lee et al., 1970; Nunes, 2008; VandenLangenberg et al., 2012).

\footnotetext{
*Comesponding author: jhknest@korea.kr

※ Received 23 September 2014; Revised 5 November 2014; Accepted 3 December 2014. This research was supported by the Golden Seed Project (Center for Horticultural Seed Development, No. 213003-04-1-SB410), Ministry of Agriculture, Food and Rural Affairs (MAFRA), Ministry of Oceans and Fisheries (MOF), Rural Development Administration (RDA), and Korea Forest Service (KFS).

(C) 2015 Korean Society for Horticultural Science
} 
Broccoli (Brassica oleracea L., var. italica) is a wellrecognized green vegetable, and is one of the most important vegetables in South Korea. It is a significant source of glucosinolates, phenols flavonoids, carotenoids, vitamins $\mathrm{C}$ and $\mathrm{E}$, as well as sugars and other phytochemicals (Balouchi et al., 2011; Bhandari and Kwak, 2014; Rosa et al., 2001). Many varieties also have antioxidant and chemopreventive effects (Chu et al., 2002; Podsedek, 2007). Several studies have been conducted on phytochemicals and their changes due to plant parts, growing seasons, years of cultivation, and broccoli genotypes. The phytochemicals studied include glucosinolates, vitamins, phenols, and falvonoids (Balouchi et al., 2011; Jeffery et al., 2003; Koh et al., 2009; Naguib et al., 2012; Nath et al., 2011; Singh et al., 2007; Vallejo et al., 2003). However, information regarding sugars composition is limited to the floret tissue only (Rosa et al., 2001). Furthermore, sugars analysis in the leaf and stem has yet to be performed, due to these tissues are generally discarded as waste material. Thus, it would be useful to characterize the accumulation pattern of sugars in the leaf and stem as well. The objectives of this study were to evaluate the influence of the growing season on glucose, fructose, and sucrose contents in different tissues (floret, leaf, stem) of various commercial broccoli cultivars, and to compare the accumulation pattern of these sugars in different tissues.

\section{Materials and Methods}

\section{Plant Materials}

Ten commercial broccoli cultivars ('AMaGi', 'BaeRiDom', 'CheongJae', 'Grace', 'Grandeur', 'JikNok No. 28', 'NokJae', 'NokYeom No. 1', 'TS-2319', and 'YuDoRi No. 1') were used for this study. The experiment was set during the spring and fall of 2011 in a randomized block design with three replicates of ten plants each, in the experimental field at the National Institute of Horticultural and Herbal Science (NIHHS), Rural Development Administration (RDA), Suwon, Korea. The sowing dates were March 5, 2011 for the spring and July 25, 2011 for the fall. For both seasons, seedlings were transplanted to the cultivation field 33 days after sowing. Seedlings were planted in rows with $50 \mathrm{~cm}$ between plants and $60 \mathrm{~cm}$ between rows. The plants were harvested 65 and 60 days after transplanting in the spring and fall seasons, respectively. During the field experiments, water, fertilizers, and pesticides were applied according to standard cultural practices at the NIHHS, RDA. After harvesting, the plants were separated into different parts (florets, stems, leaves), cut into small pieces, and freeze-dried. The samples were ground into a fine powder and stored at $-20^{\circ} \mathrm{C}$ until sugars analysis.

\section{Sugars Analysis}

The sugars (glucose, fructose, sucrose) were analyzed according to Bhandari et al. (2012) with some modifications. Briefly, powdered broccoli samples (1.0 g) were extracted with distilled water by shaking for $20 \mathrm{~min}$ in a water bath at $80^{\circ} \mathrm{C}$, centrifuged at 3,500 rpm for $5 \mathrm{~min}$, and filtered through a $0.45 \mu \mathrm{m}$ syringe filter. Samples were then analyzed using a Breeze ${ }^{\mathrm{TM}} 2$ HPLC system (Waters, Milford, MA, USA) equipped with a Waters 1525 binary HPLC pump, Waters 717plus autosampler and Waters 2410 refractive index deterctor. The separation was performed with a Kromasil $^{\circledR} 100-\mathrm{NH} 2$ column $(250 \times 4.6$ mm) (Eka Chemicals AB, Seperation products, Bohus, Sweden). Acetonitrile/ distilled water $(75 / 25, \mathrm{v} / \mathrm{v})$ was used as the mobile phase at a flow rate of $1.5 \mathrm{~mL} \cdot \mathrm{min}^{-1}$. Peaks were identified and quantified based on retention times and peak area relative to authentic standards. Authentic standards of glucose, fructose, and sucrose were obtained from Sigma-Aldrich (St. Louis, MO, USA).

\section{Statistical Analysis}

Means of three independent replicates were used for all statistical tests. Data were analyzed with SPSS (ver. 18; SPSS, Inc., Chicago, IL, USA). Significant differences among cultivars $(\mathrm{C})$, growing seasons $(\mathrm{S})$, plant parts $(\mathrm{P})$, and their interactions $(\mathrm{C} \times \mathrm{S}, \mathrm{C} \times \mathrm{P}, \mathrm{S} \times \mathrm{P}, \mathrm{C} \times \mathrm{S} \times \mathrm{P})$ were analyzed by mixed model ANOVA. Relationships among sugars were assessed by multivariate analyses using Spearman's rank order correlation coefficients (R) at $p$ $\leq 0.05$.

\section{Results and Discussion}

The contents of sugars (glucose, fructose, sucrose) in various tissues of broccoli cultivars grown during the spring and fall seasons were presented. The glucose content of floret tissue was highest among all the tested tissues in all the cultivars, comprising more than $50 \%$ of the total sugar contents. This was followed by fructose and sucrose contents in both seasons (Fig. 1). Glucose content in the spring was statistically higher (76.5 to $120.7 \mathrm{mg} \cdot \mathrm{g}^{-1} \mathrm{DW}$ ) than the fall (43.78 to $94.13 \mathrm{mg} \cdot \mathrm{g}^{-1} \mathrm{DW}$ ). However, a lower cultivar-dependent variation, as measured by coefficient of variation, was observed in the spring (13.4\%) compared to the fall season (21.6\%). Higher glucose content in the spring was previously reported by Rosa et al. (2001). The lower 
glucose level in the fall might be due to the production of glucosinolates, which was higher in the fall than in the spring (Rosa and Rodrigues, 2001). On the other hand, the higher temperature that occurs during the spring might affect carbon metabolism in various plant organs, resulting in changes in sugar partitioning, which has been demonstrated in other crops (Wolf et al., 1991). Thus, it is likely that in addition to increased biosynthetic rates, which are expected to be higher under long photoperiodic conditions, some of these sugars were translocated to the inflorescences to maintain the floral sugar pool to support the higher respiratory demand of the inflorescences, as suggested by King and Morris (1994). Fructose, which is the second major sugar, followed a similar trend to glucose with a significantly higher value in the spring (67.2 to $106.0 \mathrm{mg} \cdot \mathrm{g}^{-1}$ DW) compared to the fall (54.0 to $83.9 \mathrm{mg} \cdot \mathrm{g}^{-1} \mathrm{DW}$ ). Among the ten cultivars, the lowest and highest fructose content was found in 'NokJae' (67.2 $\mathrm{mg} \cdot \mathrm{g}^{-1} \mathrm{DW}$ ) and 'CheongJae' (110.9 $\left.\mathrm{mg} \cdot \mathrm{g}^{-1} \mathrm{DW}\right)$, respectively, with about a 1.7 -fold difference between cultivars. Sucrose, however, is found in the lowest quantity within tissue. Contrary to glucose and fructose, sucrose content in all cultivars was significantly higher in the fall than in the spring. A cultivar-dependent variation in sucrose content was most prominent compared to glucose and fructose in both seasons, with more than a 17.0- and 5.9-fold difference in the spring and fall, respectively. Total sugar content was significantly higher in all cultivars in the spring (188.0 $\left.\mathrm{mg} \cdot \mathrm{g}^{-1} \mathrm{DW}\right)$ compared to
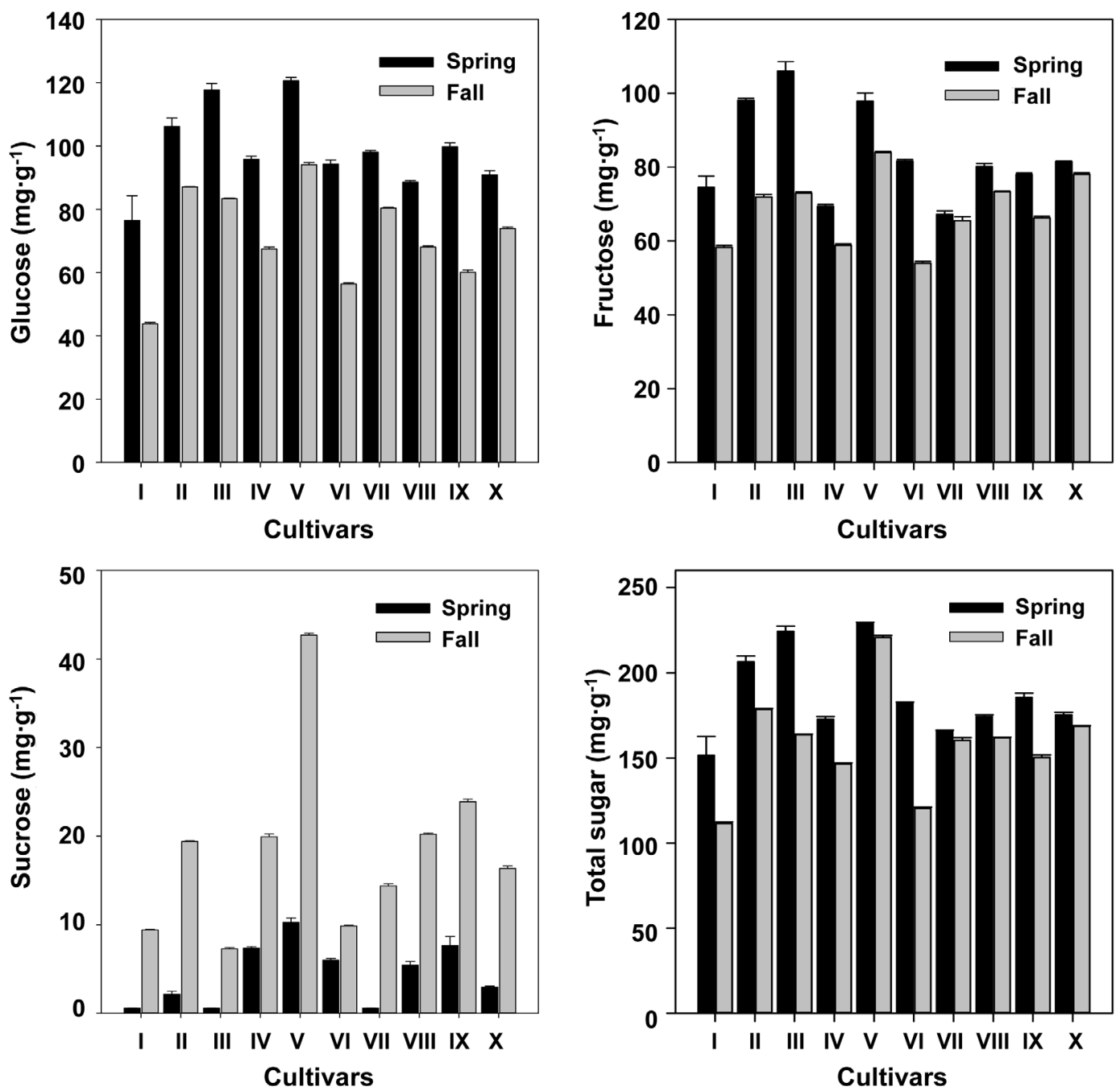

Fig. 1. Seasonal variation in contents of sugars in the floret of broccoli cultivars. Cultivars; I: 'AMaGi', II:'BaeRiDom', III: 'CheongJae', IV: 'Grace', V: 'Grandeur', VI: 'JikNok No. 28', VII: 'NokJae', VIII: 'NokYeom No. 1', IX: 'TS-2319', X: 'YuDoRi No. 1.' Values are mean $\pm \mathrm{SD}$ of three replicates. 
the fall $\left(158.5 \mathrm{mg} \cdot \mathrm{g}^{-1} \mathrm{DW}\right)$. A similar increase in glucosinolates, total phenol, and total flavonoid in the spring has been reported (Aires et al., 2011; Bhandari and Kwak, 2014). Among the cultivars tested, 'AMaGi' showed the lowest contents of sugars in both the spring $\left(151.6 \mathrm{mg} \cdot \mathrm{g}^{-1} \mathrm{DW}\right)$ and the fall (111.4 $\mathrm{mg} \cdot \mathrm{g}^{-1} \mathrm{DW}$ ), whereas 'Grandeur' showed the highest total contents of sugars in both the spring $\left(228.8 \mathrm{mg} \cdot \mathrm{g}^{-1} \mathrm{DW}\right)$ and the fall $\left(220.7 \mathrm{mg} \cdot \mathrm{g}^{-1} \mathrm{DW}\right)$. The overall values reported in this study were higher than those reported by Rosa et al. (2001), who reported values from $51.0 \mathrm{mg} \cdot \mathrm{g}^{-1} \mathrm{DW}$ to $143.0 \mathrm{mg} \cdot \mathrm{g}^{-1} \mathrm{DW}$ of total sugars in the floret of various broccoli cultivars grown in different seasons. These differences might be due to differences in genotype and other climatic factors.

Leaf tissue possessed a trend similar to floret tissue with a higher glucose content compared to fructose and sucrose. In addition, most of the cultivars exhibited significantly higher glucose content in the spring compared to the fall. However, no seasonal variation was found in the total contents of sugars. Glucose content ranged from $102.5 \mathrm{mg} \cdot \mathrm{g}^{-1}$ DW in 'YuDoRi No. 1' to $149.3 \mathrm{mg} \cdot \mathrm{g}^{-1} \mathrm{DW}$ in 'Grace' with about a 1.5-fold difference between the two cultivars (Table 1). In contrast to floret tissue, fructose content in leaf tissue was significantly higher in the fall for most of the cultivars, with the exception of 'AMaGi', and 'CheongJae'. Most of the cultivars showed a similar trend in fructose content as in sucrose, with higher values in the fall than in the spring. The seasonal and cultivar-dependent variation in sucrose content was comparatively lower in leaf tissue compared to floret parts with about a 6-fold variation between both seasons. Total free sugar in leaf tissue did not show a consistent result in that 'AMaGi' $\left(234.2 \mathrm{mg} \cdot \mathrm{g}^{-1}\right.$ DW), 'Grace' (219.8 $\mathrm{mg} \cdot \mathrm{g}^{-1} \mathrm{DW}$ ), and 'NokJae' (216.3 $\mathrm{mg} \cdot \mathrm{g}^{-1}$ DW) exhibited a significantly higher total content of free sugar in the spring, whereas all remaining cultivars showed a higher content of free sugar in the fall. Among the three types of sugars, sucrose showed the highest cultivar-dependent and seasonal variation; however, the variation was lower compared to that in floret tissue. Almost all of the cultivars showed the highest content of free sugar in leaf tissue compared to floret tissue, with the highest value of total sugar in the 'NokYeom No. 1' variety for both the spring (241.1 $\mathrm{mg} \cdot \mathrm{g}^{-1} \mathrm{DW}$ ) and fall $\left(282.1 \mathrm{mg} \cdot \mathrm{g}^{-1} \mathrm{DW}\right.$ ).

In the case of the stem, in contrast to the floret and leaf, the ratios of different free sugars were quite different with inconsistent results in all of the cultivars (Table 2). The major free sugar was any of the three free sugars, depending upon the growing seasons and cultivars; however, all the sugars content in stem was relatively higher than in floret and leaf. Sucrose, a minor free sugar in floret and leaf tissue, was drastically higher in stem, that might be due to lower acid invertase activity in the stem than in the floret and leaf (Hubbard and Pharr, 1992; Sung et al., 1994). These results suggested sweeter taste of stem compared to floret and leaf as sucrose is the one of the major free sugars responsible for the sweetness (Joesten et al., 2007). Among the cultivars, 'NokJae' exhibited the lowest sucrose content compared to the other cultivars in both seasons (43.4 $\mathrm{mg} \cdot \mathrm{g}^{-1} \mathrm{DW}$ in spring; $92.0 \mathrm{mg} \cdot \mathrm{g}^{-1} \mathrm{DW}$ in fall season) while NokYeom No. 1 exhibited comparatively higher sucrose content. Most of the cultivars showed relatively higher glucose and fructose content in the spring season

Table 1. Seasonal variation in contents of sugars in the broccoli leaf $\left(\mathrm{mg} \cdot \mathrm{g}^{-1} \mathrm{DW}\right)$.

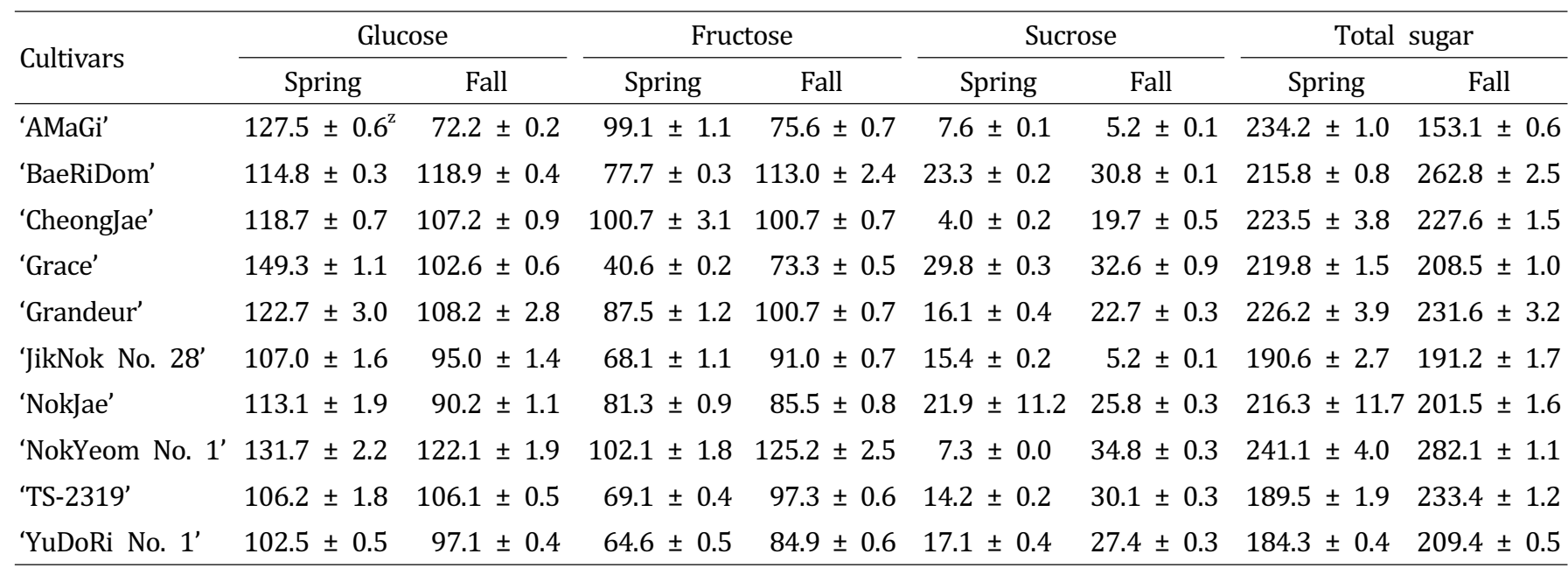

${ }^{\mathrm{z}}$ Values are mean $\pm \mathrm{SD}$ of three replicates. 
than in the fall; however, sucrose showed an opposite trend of accumulation pattern. Among the ten cultivars, 'YuDoRi No. 1' exhibited the highest total content of free sugar in both seasons with a statistically lower content in the spring season (388.1 $\mathrm{mg} \cdot \mathrm{g}^{-1} \mathrm{DW}$ ) compared to the fall (421.3 $\left.\mathrm{mg} \cdot \mathrm{g}^{-1} \mathrm{DW}\right)$. Together, the total content of free sugar in the stem was statistically higher compared to the floret and leaf parts in all of the cultivars.

The results from this study suggest that free sugar content in broccoli is significantly influenced by the genotype of the plant $(\mathrm{C})$, the growing season $(\mathrm{S})$ plant parts $(\mathrm{P})$, and their interactions (Table 3), suggesting that free sugar in broccoli cultivars is markedly influenced by several factors. Similar cultivar-dependent, season-dependent, and tissuedependent variation have been reported for other phytochemicals such as glucosinolates, vitamin C, total phenol, and total flavonoid content in broccoli cultivars (Bhandari and Kwak, 2014; Rosa and Rodrigues, 2001). To the best of our knowledge, this is the first study to examine variation in the contents of sugars in various tissues for several broccoli cultivars in different growing seasons. The presence of higher of sugars contents in the stem and leaf tissues also suggest the possible use of these plant parts.

To understand the accumulation pattern of different free sugars in broccoli cultivars and their relationships with total sugar contents, we evaluated the correlations among sugars. Regardless of genotypes, plant parts, and growing seasons, all free sugars showed significant positive relationships with total sugars. The strongest correlation existed between sucrose and total sugars $\left(r=0.829^{* *}\right)$, followed by fructose $\left(0.800^{* *}\right)$ and glucose $\left(0.721^{* *}\right)$ (Table 4$)$. Likewise, the sugars exhibited significant positive correlations to each other, with the highest correlation existing between fructose and glucose $\left(r=0.771^{* *}\right)$.

In conclusion, significant differences in the level of individual and total free sugars in broccoli in relation to genotypes,

Table 2. Seasonal variation in contents of sugars in the broccoli stem $\left(\mathrm{mg} \cdot \mathrm{g}^{-1} \mathrm{DW}\right)$.

\begin{tabular}{|c|c|c|c|c|c|c|c|c|}
\hline \multirow{2}{*}{ Cultivars } & \multicolumn{2}{|c|}{ Glucose } & \multicolumn{2}{|c|}{ Fructose } & \multicolumn{2}{|c|}{ Sucrose } & \multicolumn{2}{|c|}{ Total sugar } \\
\hline & Spring & Fall & Spring & Fall & Spring & Fall & Spring & Fall \\
\hline 'AMaGi' & $123.1 \pm 3.2^{z}$ & $82.0 \pm 0.8$ & $108.1 \pm 5.8$ & $72.8 \pm 0.2$ & $94.4 \pm 2.3$ & $94.9 \pm 0.2$ & $325.7 \pm 6.7$ & $249.7 \pm 0.9$ \\
\hline ‘BaeRiDom’ & $113.7 \pm 1.0$ & $145.7 \pm 2.6$ & $105.3 \pm 1.4$ & $147.8 \pm 1.9$ & $149.5 \pm 1.8$ & $125.8 \pm 1.2$ & $368.5 \pm 4.1$ & $419.3 \pm 5.6$ \\
\hline 'CheongJae' & $140.4 \pm 2.5$ & $136.1 \pm 2.3$ & $132.7 \pm 0.7$ & $125.7 \pm 1.5$ & $82.5 \pm 2.8$ & $118.2 \pm 2.3$ & $355.5 \pm 0.9$ & $380.0 \pm 6.0$ \\
\hline 'Grace' & $162.0 \pm 3.2$ & $81.9 \pm 1.3$ & $121.8 \pm 2.8$ & $71.2 \pm 0.2$ & $66.7 \pm 1.0$ & $156.9 \pm 1.0$ & $350.5 \pm 6.9$ & $309.9 \pm 2.3$ \\
\hline 'Grandeur' & $142.2 \pm 1.4$ & $115.0 \pm 0.7$ & $124.8 \pm 1.0$ & $99.7 \pm 0.2$ & $74.2 \pm 1.0$ & $120.3 \pm 1.9$ & $341.1 \pm 1.8$ & $335.0 \pm 2.5$ \\
\hline 'JikNok No. 28' & $134.8 \pm 9.7$ & $112.1 \pm 1.9$ & $124.4 \pm 5.6$ & $101.6 \pm 0.5$ & $86.3 \pm 3.0$ & $115.2 \pm 2.8$ & $345.5 \pm 14.5$ & $328.9 \pm 3.9$ \\
\hline 'NokJae' & $157.5 \pm 4.9$ & $162.9 \pm 1.5$ & $135.6 \pm 1.0$ & $133.1 \pm 3.3$ & $43.4 \pm 0.2$ & $92.0 \pm 0.7$ & $336.5 \pm 5.8$ & $387.9 \pm 5.4$ \\
\hline 'NokYeom No. 1' & $61.6 \pm 0.7$ & $81.7 \pm 0.2$ & $56.6 \pm 6.3$ & $78.0 \pm 0.5$ & $144.9 \pm 1.1$ & $156.8 \pm 2.0$ & $263.1 \pm 5.3$ & $316.5 \pm 2.4$ \\
\hline 'TS-2319’ & $109.2 \pm 0.6$ & $101.2 \pm 0.3$ & $93.8 \pm 1.8$ & $96.2 \pm 0.6$ & $134.2 \pm 1.9$ & $177.1 \pm 3.5$ & $337.2 \pm 1.8$ & $374.4 \pm 2.8$ \\
\hline 'YuDoRi No. 1' & $148.2 \pm 1.3$ & $138.7 \pm 0.7$ & $134.3 \pm 0.7$ & $132.3 \pm 10.5$ & $105.6 \pm 0.5$ & $150.3 \pm 0.9$ & $388.1 \pm 2.4$ & $421.3 \pm 11.9$ \\
\hline
\end{tabular}

${ }^{\mathrm{z}}$ Values are mean \pm SD of three replicates.

Table 3. Results of analysis of variance for the contents of sugars in broccoli cultivars

\begin{tabular}{lcccc}
\hline Source of variance & Glucose & Fructose & Sucrose & Total sugar \\
\hline Cultivar (C) & $* * *$ & $* * *$ & $* * *$ & $* * *$ \\
Season (S) & $* * *$ & $* * *$ & $* * *$ & $* * *$ \\
Plant Parts (P) & $* * *$ & $* * *$ & $* * *$ & $* * *$ \\
C X S & $* * *$ & $* * *$ & $* * *$ & $* * *$ \\
C X P & $* * *$ & $* * *$ & $* * *$ & $* * *$ \\
S X P & $* * *$ & $* * *$ & $* * *$ & $* * *$ \\
C X S X P & $* * *$ & $* * *$ & &
\end{tabular}

***, Significance level is $p<0.001$. 
Table 4. Correlation coefficients for free sugar content in broccoli cultivars.

\begin{tabular}{llcc}
\hline Free sugars & Glucose & Sucrose & Total sugar \\
\hline Fructose & $0.771^{* *}$ & $0.390^{* *}$ & $0.800^{* *}$ \\
Glucose & & $0.253^{* *}$ & $0.721^{* *}$ \\
Sucrose & & & $0.829^{* *}$ \\
\hline
\end{tabular}

**, Significance level is $p<0.01$.

tissue type, and growing season were observed. Floret tissue exhibited consistent results throughout the cultivars, with significantly higher sugars contents in the spring compared to the fall. Leaf and stem tissue showed different accumulation patterns depending on the genotype of broccoli. The 'Grandeur' broccoli had the highest sugars contents in the floret, suggesting its superiority in terms of sugar content. In addition, leaf and stem tissue possessed comparatively higher sugar content compared to floret tissue in all of the cultivars, indicating that leaves and stems are also good sources of sugars.

\section{Literature Cited}

Aires, A., C. Fernandes, R. Carvalho, R.N. Bennett, M.J. Saavedra, and E.A.S. Rosa. 2011. Seasonal effects on bioactive compounds and antioxidant capacity of six economically important Brassica vegetables. Molecules 16:6816-6832.

Auerswald, H., D. Schwarz, C. Kornelson, A. Krumbein, and B. Bruckner. 1999. Sensory analysis, sugar and acid content of tomato at different EC values of the nutrient solution. Sci. Hortic. 82:227-242.

Balouchi, Z., G.-A. Peyvast, M. Ghasemnezhad, and M. Saadatian. 2011. Changes of antioxidant compounds of broccoli (Brassica oleracea L. var. Italica) during storage at low and high temperatures. South-West. J. Hortic. Biol. Environ. 2:193-212.

Bhandari, S.R., S. Basnet, K.H. Chung, K.-H. Ryu, and Y.-S. Lee. 2012. Comparisons of nutritional and phytochemical property of genetically modified CMV-resistant red pepper and its parental cultivar. Hort. Environ. Biotechnol. 53:151-157.

Bhandari, S.R. and J.H. Kwak. 2014. Seasonal variation in phytochemicals and antioxidant activities in different tissues of various Broccoli cultivars. Afr. J. Biotechnol. 13:604-615.

Cheng, W.-H., A. Endo, L. Zhou, J. Penney, H.-C. Chen, A. Arroyo, A., P. Leon, E. Nambara, T. Asami, M. Seo, T. Koshiba, and J. Sheen. 2002. A unique short-chain dehydrogenase/reductase in Arabidopsis glucose signaling and abscisic acid biosynthesis and functions. Plant Cell 14:2723-2743.

Chu, Y.-F., J. Sun, X. Wu, and R.H. Liu. 2002. Antioxidant and anti-proliferative activities of common vegetables. J. Agr. Food Chem. 50:6910- 6916.
Duffus, C.M. and J.H. Duffus. 1984. Carbohydrate metabolism in plants. Longman Group. Harlow, UK.

Hodges, D.M., K.D. Munro, C.F. Forney, and K.B. McRae. 2006. Glucosinolate and free sugar content in cauliflower (Brassica oleracea var. botrytis cv. Freemont) during controlled-atmosphere storage. Postharvest Biol. Technol. 40:123-132.

Hounsome, N., B. Hounsome, D. Tomos, and G. Edwards-Jones. 2008. Plant metabolites and nutritional quality of vegetables. J. Food Sci. 73:R48-R65.

Hubbard, N.L. and D.M. Pharr. 1992. Developmental changes in carbohydrate concentration and activities of sucrose metabolizing enzymes in fruits of two Capsicum anmuum L. genotypes. Plant Sci. 86:33-39.

Jeffery, E.H., A.F. Brown, A.C. Kurilich, A.S. Keck, N. Matusheski, B.P. Klein, and J.A. Juvik. 2003. Variation in content of bioactive components in broccoli. J. Food Comp. Anal. 16:323-330.

Joesten, M., M.E. Castellion, and J.L. Hogg. 2007. The world of chemistry: Essentials. $4^{\text {th }}$ Ed. Thomson Brooks/Cole, Belmont, CA, USA.

King, G.A. and S.C. Morris. 1994. Early compositional changes during postharvest senescence of broccoli. J. Am. Soc. Hortic. Sci. 119:1000-1005.

Koh, E., K.M.S. Wimalasiri, A.W. Chassy, and A.E. Mitchell. 2009. Content of ascorbic acid, quercetin, kaempferol and total phenolics in commercial broccoli. J. Food Comp. Anal. 22:637-643.

Lee, C.Y., R.S. Shallenberger, and M.T. Vittum. 1970. Free sugars in fruits and vegetables. New York's Food \& Life Science Bulletin. No. 1. Cornell Univ., Ithaca, NY, USA.

Malundo, T.M.M., R.L. Shewfelt, and J.W. Scott. 1995. Flavor quality of fresh tomato (Lycopersicon esculentum Mill.) as affected by sugar and acid levels. Postharvest Biol. Technol. 6:103-110.

Naguib, A.E.M.M., F.K. El-Baz, Z.A. Salama, H.A.E.B. Hanaa, H.F. Ali, and A.A. Gaafar, 2012. Enhancement of phenolics, flavonoids and glucosinolates of broccoli (Brassica olaracea, var. italica) as antioxidants in response to organic and bioorganic fertilizers. J. Saudi Soc. Agr. Sci. 11:135-142.

Nath, A., B. Bagchi, L.K. Misra, and B.C. Deka. 2011. Changes in post-harvest phytochemical qualities of broccoli florets during ambient and refrigerated storage. Food Chem. 127:1510-1514.

Nunes, M.C.N. 2008. Color atlas of postharvest quality of fruits and vegetables. Wiley-Blackwell Publishing, Ames, IA, USA.

Podsedek, A. 2007. Natural antioxidants and antioxidant capacity of Brassica vegetables: a review. LWT- Food Sci. Technol. 40:1-11.

Rosa, E.A.S. and A.S. Rodrigues. 2001. Total and individual glucosinolate content in 11 broccoli cultivars grown in early and late seasons. HortScience 36:56-59.

Rosa, E., M. David, and M.H. Gomes. 2001. Glucose, fructose and sucrose content in broccoli, white cabbage and Portuguese cabbage grown in early and late seasons. J. Sci. Food Agr. 
81:1145-1149.

Schonhof, I., A. Krumbein, and B. Bruckner. 2004. Genotypic effects on glucosinolates and sensory properties of broccoli and cauliflower. Nahrung-Food 48:25-33.

Semchyshyn, H.M., J. Miedzobrodzki, M.M. Bayliak, L.M. Lozinska, and B.V. Homza. 2014. Fructose compared to glucose is more a potent glycoxidation agent in vitro, but not under carbohydrateinduced stress in vivo: potential role of antioxidant and antiglycation enzymes. Carbohydr. Res. 384:61-69.

Sims, C.A. and R. Golaszewski. 2003. Vegetable flavor and changes during postharvest storage, p. 331-340. In: Bartz, J.A. and J.K. Brecht (eds.). Postharvest physiology and pathology of vegetables. Marcel Dekker, NY, USA.

Singh, J., A.K. Upadhyay, K. Prasad, A. Bahadur, and M. Rai. 2007. Variability of carotenes, vitamin C, E and phenolics in
Brassica vegetables. J. Food Comp. Anal. 20:106-112.

Sung, S.S., W.J. Sheih, D.R. Geiger, and C.C. Black. 1994. Growth, sucrose synthase, and invertase activities of developing Phaseolus vulgaris L. fruits. Plant Cell Environ. 17:419-426.

Vallejo, F., F.A. Tomas-Barberan, and C. Garcia-Viguera. 2003. Effect of climatic and sulphur fertilisation conditions, on phenolic compounds and vitamin $\mathrm{C}$, in the inflorescences of eight broccoli cultivars. Eur. Food Res. Technol. 216:395-401.

VandenLangenberg, K.M., P.C. Bethke, and J. Nienhuis. 2012. Patterns of fructose, glucose, and sucrose accumulation in snap and dry bean (Phaseolus vulgaris) pods. HortScience 47:874-878.

Wolf, S., A. Marani, and J. Rudich. 1991. Effect of temperature on carbohydrate metabolism in potato plants. J. Exp. Bot. 42:619-625. 